\title{
Repair of Uterine Rupture during Second Trimester Leading to Successful Pregnancy Outcome: Case Study and Literature's Review
}

\author{
Tae Sugawara, MD ${ }^{1}$ Masaki Ogawa, MD, $\mathrm{PhD}^{1,2}$ Toshinobu Tanaka, MD, PhD ${ }^{1}$ \\ ${ }^{1}$ Department of Obstetrics and Gynecology, Akita University School of \\ Medicine, Hondo, Akita, Japan \\ 2 Perinatal Medical Center, Tokyo Women's Medical University, \\ Address for correspondence Masaki Ogawa, MD, PhD, Perinatal \\ Medical Center, Tokyo Women's Medical University, Kawadacho 8-1, \\ Shinjuku, Tokyo 1628666, Japan (e-mail: masakiogawa3@gmail.com).
} Shinjuku, Tokyo, Japan

Am J Perinatol Rep 2014;4:9-12.

\begin{abstract}
Keywords

- fleece-coated fibrin glue

- second trimester

- uterine rupture

It was thought to be impossible to prolong the pregnancy in a case of uterine rupture in the second trimester. We encountered a case of rupture of the pregnant uterus in early mid-trimester, which we repaired with suture and overlapping of collagen fleece coated with fibrin glue, resulting in pregnancy prolongation until the 34th week. Our case and five previously reported cases were reviewed. Pregnant uterine rupture in mid-trimester could be repaired with suture and overlapping of collagen fleece in the absence of placenta percreta.
\end{abstract}

Rupture of the pregnant uterus caused by separation of uterine myometrium is thought to be a life-threatening condition for the mother and fetus. For management of this condition, cesarean delivery may be suitable during the viable term of the fetus, followed by repair of the uterus. Hysterectomy may be appropriate if bleeding is uncontrolled. ${ }^{1}$ However, during the previable term, we do not have any knowledge about what approach is better, cesarean section, repair, or hysterectomy. ${ }^{1}$

We encountered a case of rupture of the pregnant uterus that occurred during the early second trimester. Repair of the rupture site using collagen fleece led to successful pregnancy prolongation. In this case series study, we have reviewed our case and five previously reported cases, and have evaluated how repair of the pregnant ruptured uterus occurring in the second trimester would be managed.

\section{Materials and Methods}

\section{Case}

A 28-year-old Japanese woman, gravida 3 and para 2, was referred to our hospital with progressive abdominal pain after coitus at $14+5$ weeks of gestation. Her pregnant history was (1) interruption, (2) cesarean section with low transverse incision due to breech presentation, and (3) cesarean section with high transverse incision due to placental previa accreta, which needed intravenous methotrexate therapy and uterine arterial embolization. At admission, her vital signs were normal; blood pressure: $81 / 42 \mathrm{~mm} \mathrm{Hg}$; pulse: 66/min. Her hematocrit was $34.8 \%$, hemoglobin $9.5 \mathrm{~g} / \mathrm{dL}$, and white blood cell count $7,400 / \mu \mathrm{L}$. Ultrasonography revealed echo-free space in the vesicouterine pouch, suggesting hemoperitoneum. Six hours later, intra-abdominal bleeding increased, and signs of shock index were not observed, so minilaparotomy was performed. Hemoperitoneum $(1,300 \mathrm{~g}$ of blood loss) was found with a myometrium defect on the uterine anterior wall, suggesting rupture of scarred uterus (-Fig. 1a). Her family did not give consent for total hysterectomy. Repair of the ruptured uterus was performed with three-layered separate stitches suture of 3-0 polyglactin 910 (Coated Vicryl, Ethicon, Inc., Somerville, NJ), subsequently covered using fleece-coated fibrin glue (TachoComb, CSL Behring, King of Prussia, PA). Her total blood loss was $1,745 \mathrm{~g}$, for which she received four units of red blood cells. To prevent uterine rupture, she received continuous infusion of a tocolytic agent, ritodrine, with bed rest. We planned a laparotomy, as a second-look operation, to rule out placental percreta, and it was performed at 28 weeks of gestation. The rupture site was received

September 6, 2013 accepted after revision

October 12, 2013

published online

December 17, 2013
Dol http://dx.doi.org/

10.1055/s-0033-1361926. ISSN 2157-6998.
Copyright (c) 2014 by Thieme Medical Publishers, Inc., 333 Seventh Avenue, New York, NY 10001, USA. Tel: +1(212) 584-4662.
License terms

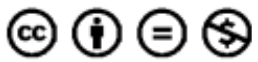



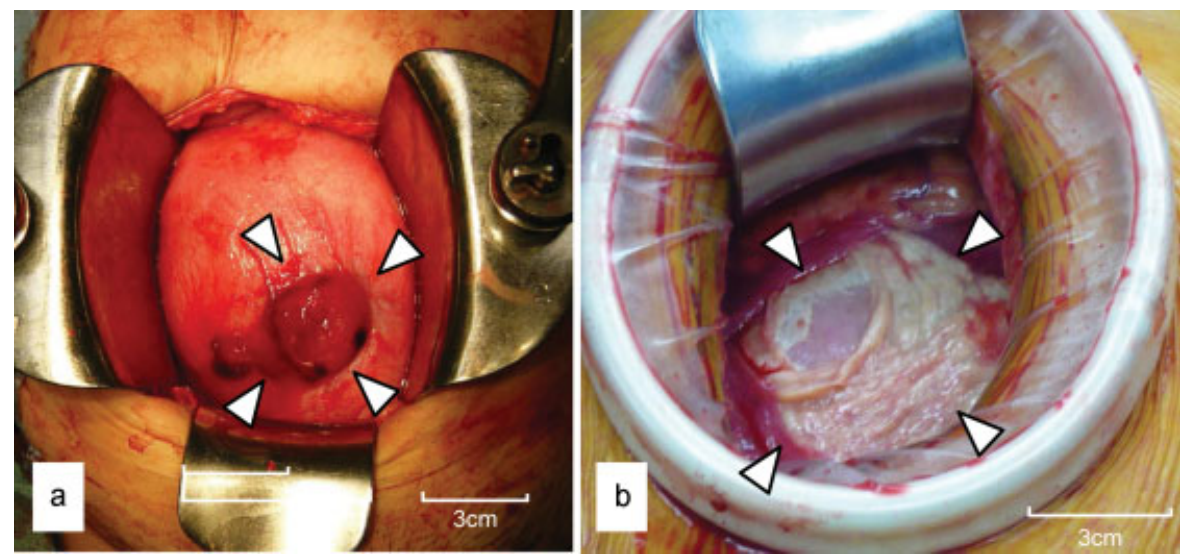

Fig. 1 (a) Myometrium defect revealed on uterine surface (white arrows) at $14+5$ weeks gestation and the placenta with continuous bleeding were represented. (b) White tissue (white arrows) derived from collagen fleece coated with fibrin glue covered the previous uterine wall defect at diagnostic laparotomy at 28th week.

completely covered with white tissue. No evidence of placen-

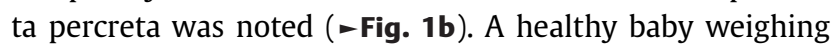
$2,600 \mathrm{~g}$ was delivered by elective cesarean section with normal Apgar scores at $34+6$ gestational weeks.

\section{Five Other Cases}

A computer search was done using the terms "uterine rupture," "second trimester," and "repair" through the PubMed engine. ${ }^{2}$ Twenty-seven articles were checked and five documents were extracted. The information from each is summarized in - Tables $\mathbf{1}$ and $\mathbf{2}$.

\section{Discussion}

Rupture of the pregnant uterus was thought to be a rare disorder, that is, less than $0.05 \%$ of pregnancies. ${ }^{3}$ There has been an upward trend in threatened uterine rupture recently as the number of postcesarean section pregnancies has increased. ${ }^{4-6}$ Eden et $\mathrm{al}^{7}$ reported that rupture due to previous cesarean, referred to as scarred uterus, accounted for approximately $20 \%$ of all uterine ruptures in the 1980 s. Furthermore, Rachagan et $\mathrm{al}^{8}$ emphasized its frequency was over 50\% in 1986. Pregnancy termination was indicated if uterine rupture occurred; hysterectomy may be needed in some instances. Repair of the ruptured uterus could possibly lead to pregnancy prolongation, and consequently could yield favorable maternal and fetal or neonatal outcomes.

Shirata et $\mathrm{al}^{9}$ reported an interesting case of unscarred uterine rupture that occurred at 24 gestational weeks with massive hemoperitoneum of 2,200 g, which was repaired by combined therapy of absorbable suture and covering with fleece-coated fibrin glue, and then subsequently yielded favorable pregnancy prolongation until 35 gestational weeks. Their management was similar to our case. These two cases may suggest the utility of a collagen sheet for repair of uterine dehiscence. Collagen fleece has recent- ly been used in many surgeries as a hemostatic agent, such as to treat pneumothorax. Collagen fleece maintains the strength of tissue by adhering to the tissue and forming a three-dimensional structure. Matsutani and Ozeki ${ }^{10}$ examined the efficacy of overlapping of collagen fleece to repair pleural defects. They concluded that pleural circular defects $6 \mathrm{~mm}$ in diameter with overlapping of collagen fleece could withstand airway pressure of $40 \mathrm{cmH}_{2} \mathrm{O}$. They explained that collagen fleece resulted in adhesion of pleura. Therefore, collagen fleece may reinforce the uterine defect.

There have been several reports, ${ }^{9,11-14}$ concerning repair of uterine ruptures in the second trimester using suture and/ or patching. These five cases and our case are reviewed and summarized in - Tables 1 and $\mathbf{2}$. The putative cause of uterine rupture was mainly previous cesarean in early mid-trimester. The initial symptom was lower abdominal pain caused by hemoperitoneum. In complete rupture, rupture size was larger than in cases with incomplete rupture. All cases achieved sufficient pregnancy prolongation of more than 33 gestational weeks. In four cases, the placenta was located just beneath the rupture site. In these cases, it was impossible to distinguish uterine rupture and placenta percreta. Roeters et $\mathrm{al}^{15}$ reported a case in which placenta percreta at 14 gestational weeks was repaired and subsequently resulted in pregnancy prolongation until the 35th week. However, they criticized their management because it did not rule out the possibility of a severe complication, that is, recurrence of hemoperitoneum due to placenta percreta. In our case, we performed diagnostic laparotomy to rule out placenta percreta. Repeated ultrasonographic examination may needed for diagnosis of percreta.

In conclusion, uterine rupture in mid-trimester could be repaired with suture and overlapping of collagen fleece, if placenta percreta is absent. When placenta percreta is suspected, precise ultrasound monitoring or diagnostic laparotomy might be necessary after repair. 

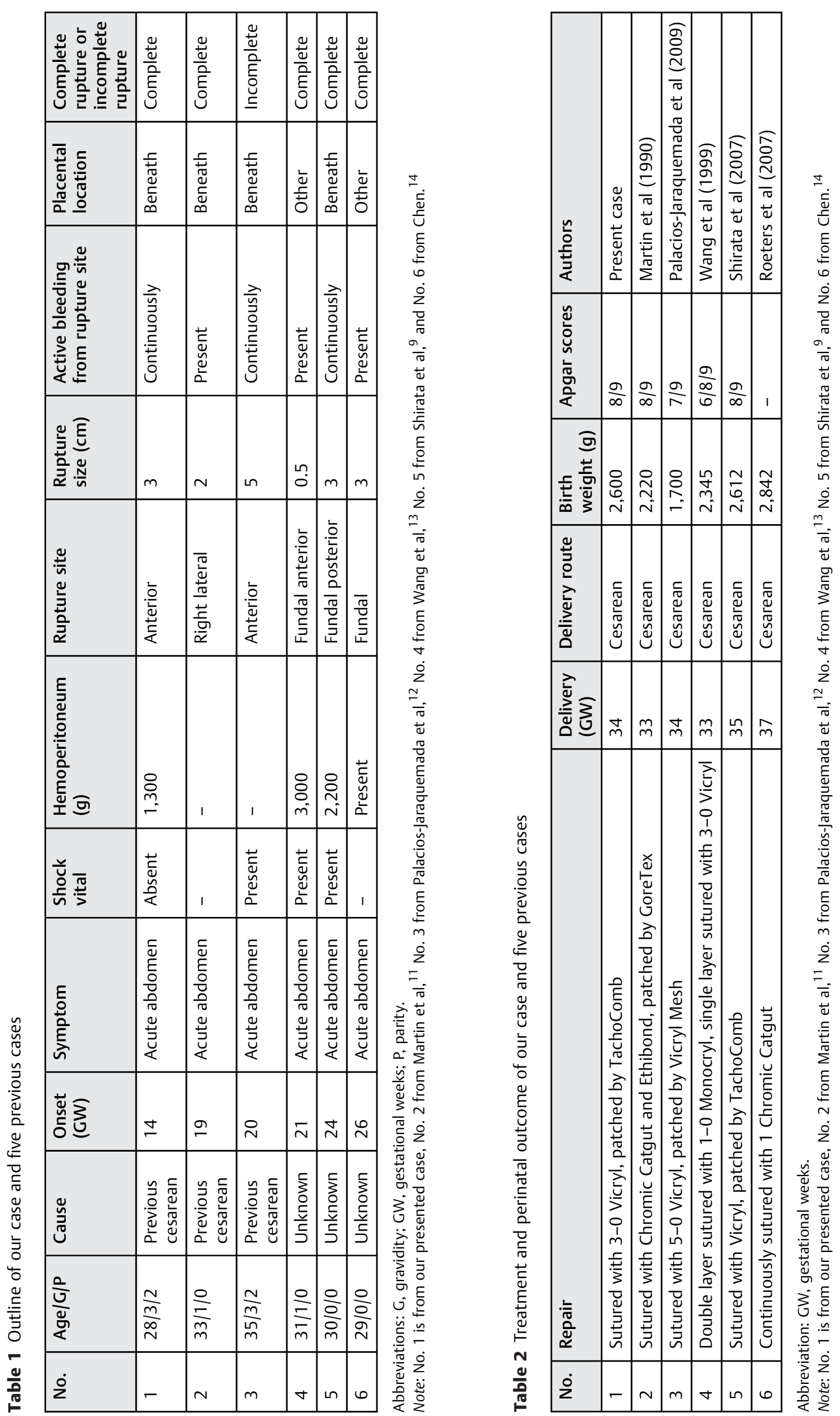
12 Repairing for Uterine Rupture in the Second Trimester Sugawara et al.

\section{Conflict of Interest}

The authors report no conflicts of interest. The authors are responsible for the content and writing the article.

\section{References}

1 Smith JF, Wax JR. Rupture of the unscarred uterus. in UpToDate. Available at: http://www.uptodate.com/contents/rupture-of-theunscarred-uterus. Accessed February 17, 2012

2 PubMed Available at. Available at: http://www.ncbi.nlm.nih.gov/ pubmed/. Accessed January 14, 2013

3 Hofmeyr GJ, Say L, Gülmezoglu AM. WHO systematic review of maternal mortality and morbidity: the prevalence of uterine rupture. BJOG 2005;112(9):1221-1228

4 Zwart JJ, Richters JM, Ory F, de Vries JI, Bloemenkamp KW, van Roosmalen J. Uterine rupture in The Netherlands: a nationwide population-based cohort study. BJOG 2009;116(8):1069-1078, discussion 1078-1080

5 Kieser KE, Baskett TF. A 10-year population-based study of uterine rupture. Obstet Gynecol 2002;100(4):749-753

6 Miller DA, Goodwin TM, Gherman RB, Paul RH. Intrapartum rupture of the unscarred uterus. Obstet Gynecol 1997;89(5 Pt 1):671-673

7 Eden RD, Parker RT, Gall SA. Rupture of the pregnant uterus: a 53year review. Obstet Gynecol 1986;68(5):671-674

8 Rachagan SP, Raman S, Balasundram G, Balakrishnan S. Rupture of the pregnant uterus-a 21-year review. Aust N Z J Obstet Gynaecol 1991;31(1):37-40
9 Shirata I, Fujiwaki R, Takubo K, Shibukawa T, Sawada K. Successful continuation of pregnancy after repair of a midgestational uterine rupture with the use of a fibrin-coated collagen fleece (TachoComb) in a primigravid woman with no known risk factors. Am J Obstet Gynecol 2007;197(4):e7-e9

10 Matsutani N, Ozeki Y. Pleural defect repair with an overlapping method using fibrin glue-coated collagen fleece. Surg Today 2011; 41(9):1234-1237

11 Martin JN Jr, Brewer DW, Rush LV Jr, Martin RW, Hess LW, Morrison JC. Successful pregnancy outcome following mid-gestational uterine rupture and repair using Gore-Tex soft tissue patch. Obstet Gynecol 1990;75(3 Pt 2):518-521

12 Palacios-Jaraquemada JM, Fiorillo A, von Petery F, Colaci D, Leguizamón $\mathrm{G}$. Uterine repair and successful pregnancy after myometrial and placental rupture with massive haemoperitoneum. BJOG 2009;116(3):456-460

13 Wang PH, Chao HT, Too LL, Yuan CC. Primary repair of cornual rupture occurring at 21 weeks gestation and successful pregnancy outcome. Hum Reprod 1999;14(7):1894-1895

14 Chen FP. Term delivery after repair of a uterine rupture during the second trimester in a previously unscarred uterus: a case report. J Reprod Med 2007;52(10):981-983

15 Roeters AE, Oudijk MA, Heydanus R, Bruinse HW. Pregnancy outcome after intra-abdominal bleeding due to placenta percreta at 14 weeks of gestation. Obstet Gynecol 2007;109(2 Pt 2): 574-576 